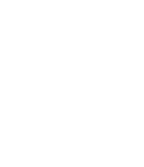
ANNUAL Further
REVIEWS

Click here for quick links to Annual Reviews content online, including:

- Other articles in this volume

- Top cited articles

- Top downloaded articles

- Our comprehensive search

\section{An Integrated Device View on Photo-Electrochemical Solar-Hydrogen Generation}

\section{Miguel A. Modestino and Sophia Haussener}

School of Engineering, École Polytechnique Fédérale de Lausanne, 1015 Lausanne, Switzerland; email: miguel.modestino@epfl.ch, sophia.haussener@epfl.ch

\section{Keywords}

First published online as a Review in Advance on January 30, 2015

The Annual Review of Chemical and Biomolecular Engineering is online at chembioeng.annualreviews.org

This article's doi:

10.1146/annurev-chembioeng-061114-123357

Copyright (c) 2015 by Annual Reviews.

All rights reserved solar fuels, photo-electrochemistry, solar devices, solar water splitting

\section{Abstract}

Devices that directly capture and store solar energy have the potential to significantly increase the share of energy from intermittent renewable sources. Photo-electrochemical solar-hydrogen generators could become an important contributor, as these devices can convert solar energy into fuels that can be used throughout all sectors of energy. Rather than focusing on scientific achievement on the component level, this article reviews aspects of overall component integration in photo-electrochemical water-splitting devices that ultimately can lead to deployable devices. Throughout the article, three generalized categories of devices are considered with different levels of integration and spanning the range of complete integration by one-material photo-electrochemical approaches to complete decoupling by photovoltaics and electrolyzer devices. By using this generalized framework, we describe the physical aspects, device requirements, and practical implications involved with developing practical photo-electrochemical water-splitting devices. Aspects reviewed include macroscopic coupled multiphysics device models, physical device demonstrations, and economic and life cycle assessments, providing the grounds to draw conclusions on the overall technological outlook. 


\section{INTRODUCTION}

Solar energy provides a renewable and clean energy source with an exhaustive but untapped potential, which can significantly contribute to a renewable energy future. The solar energy potential exceeds the potential of all other renewable energy sources combined and is substantially larger than the current global energy demand (1). For example, solar energy delivers the earth's ultimate recoverable oil resource in just 1.5 days. Covering only $0.1 \%$ of the earth surface, e.g., in the Saharan region, with $10 \%$ efficiency solar energy conversion devices would provide enough energy to satisfy the current global energy demand.

A variety of approaches exist to directly convert solar energy into chemical energy and possibly into a storable, high-energy density fuel, such as hydrogen. These approaches include hightemperature solar thermochemistry by water-splitting redox cycles $(2,3)$, photo-electrochemistry and photocatalysis (4-7), solar biomass gasification processes $(8,9)$, and photobiology via photosynthetic processes (10). Only by implementing sustainable, efficient, stable, and economically viable solar devices and their assemblies in large-scale systems can a substantial impact on our fuel economy be achieved (11-14). Whereas biological photosynthesis systems, i.e., plants, show annually averaged efficiencies (defined as the heat of combustion of the accumulated biomass divided by the solar irradiation) in the range of $1 \%(10)$, demonstrated efficiencies of artificial or technical systems are in the range of $1-2 \%$ for thermochemical water and $\mathrm{CO}_{2}$ splitting by redox cycles $(3,15,16)$, up to $18 \%$ for photo-electrochemical (PEC) water splitting (17-19), and 20-30\% for solar biomass steam gasification for the production of synthesis gas (8). The latter requires the input of an additional, potentially nonabundant fuel (biomass). Solar-driven thermochemical approaches use concentrated solar radiation as the process heat to drive high-temperature thermochemical reactions. Throughout this review, photo-electrochemical approaches are considered to be the family of processes that use photon energy to generate charge carriers in a semiconductor, which are used to drive the electrochemical reactions; these processes include but are not limited to solar-chemical transformation in photocatalytic materials. Economically, solar-driven thermochemical water splitting and PEC water electrolysis are projected to lead to similar levelized costs of hydrogen (20-22). The power of the demonstrated thermochemical water- and $\mathrm{CO}_{2}$-splitting systems is usually in the range of $1-10 \mathrm{~kW}$, with a few demonstration projects in the $100-\mathrm{kW}$ range (23), and can remain operationally stable over many days and hundreds of cycles (15). The PEC reactors, however, are laboratory-scale demonstrations in the range of $0.1-1 \mathrm{~W}$ and operate stably for only hours $(24,25)$. One possible reason for the technologically less-advanced, smaller-scale, and less-stable status of current PEC water-splitting demonstrations, compared with thermochemical demonstrations (despite similar research history and acknowledging the different research challenges), is the limited number of investigations focusing on complete PEC devices and integration of the various components in a working prototype. The realization of such devices is challenging, as it requires the integration of suitable photoabsorbers, charge generators, and electrocatalysts, which must be embedded in or interconnected by conducting phases (both ionic and electronic), while ensuring product separation. The individual performance of these coupled device components greatly influences the performance of the integrated reactor $(17,25-$ $27)$, largely depending on the design and operational conditions $(28,29)$, which must function in compatible conditions throughout the device.

In this review we focus on integrating aspects of PEC devices, considering and discussing three possible device configurations for approaching PEC fuel processing with different integration levels: (a) one-material approaches using catalytically active solar absorbers with semiconductorelectrolyte junctions for charge separation, $(b)$ integrated photoabsorber and catalysis approaches using thin, nonabsorbing, and conducting protection layers at the semiconductor-electrolyte 
interface connected to the catalytic sites, and (c) decoupled and externally wired photovoltaics (PV) plus electrolyzer devices. These three device types span the full range of PEC solar fuel processes, from integrated one-material approaches to completely separated processes, such as externally wired PV plus electrolyzer systems.

\section{DEVICE CONFIGURATION CHARACTERIZATION}

Since the inception of the concept of PEC solar-water splitting more than 40 years ago, several attempts to demonstrate functioning solar-fuel devices have been made (17, 19, 24-26, 30-36). But to a large extent, the problem of building practical systems remains unsolved owing to their complex and simultaneously desired characteristics: (a) continuous, efficient, and stable productions of fuel under illumination; $(b)$ long lifetimes; $(c)$ economic viability; $(d)$ scalability of components (earth-abundance of materials can become a significant challenge for systems to reach the required terawatt scale); (e) net energy surplus over the device life cycle; and $(f)$ operation under safe and environmentally benign conditions. To date, no single device has demonstrated all of these characteristics. The simplest conception of a solar-fuel generator requires light-absorption components, materials for the oxidation and reduction of the feed streams and fuel processing, an electrolyte to allow ionic species to migrate between redox reaction sites, and a separation mechanism for the generated fuel. Based on these fundamental requirements, different components can be selected for the fabrication of devices, and their required performance characteristics and arrangement should be guided by design rules from computational modeling, device experimentation, technoeconomic considerations, and life cycle analyses (LCA). Recently, Jacobsson et al. (37) described the space of possible device configurations for solar-fuel production, going from fully integrated PECs to fully decoupled PV panels and distributed electrolyzers connected to the electrical grid. The description presented in their analysis is worth highlighting, as the fundamental aspects and net inputs (sunlight and feed reactants), as well as outputs (fuel and byproducts), are virtually the same, even if different device configurations might require the addition of peripheral components (e.g., current invertors, wires for electrical connections, encapsulation components). Figure 1 presents a generalized scheme of the physical processes and components involved in a solar-hydrogen PEC device and the corresponding three major device configurations with different levels of component integration.

Throughout this review, we refer to PEC devices as those devices in which the electrochemical water-splitting reactions take place directly on the photoabsorber, i.e., the semiconductor, and at the semiconductor-electrolyte interface. The semiconductor-electrolyte interface is simultaneously used for the separation of photo-induced charge carrier pairs, and the charge carriers must cross this interface. For PEC devices, the choice of a suitable single-semiconductor material simultaneously working as an efficient, earth-abundant, and inexpensive photoabsorber, a charge separator, and a selective water-splitting catalyst while being able to operate stably both in the dark and under illumination in a possibly highly corrosive environment has proven to be difficult (38).

Consequently, the idea of using multiple materials to conduct the individual functions has recently become more popular. The second group of devices discussed in this review incorporate a thin nonabsorbing and conducting protection layer that is applied on the photoabsorber, i.e., at the semiconductor-electrolyte interface. These devices are referred to as photo-electrochemical devices throughout the review.

The protecting layer can serve as a charge transfer layer between the photoabsorber and the catalytic sites or could be composed of a conformal coating of stable electrocatalyst. Effectively, in these device approaches, radiation absorption and catalysis are separated and performed by two different materials. The advantage of distributing the absorption and catalysis functions to 
a

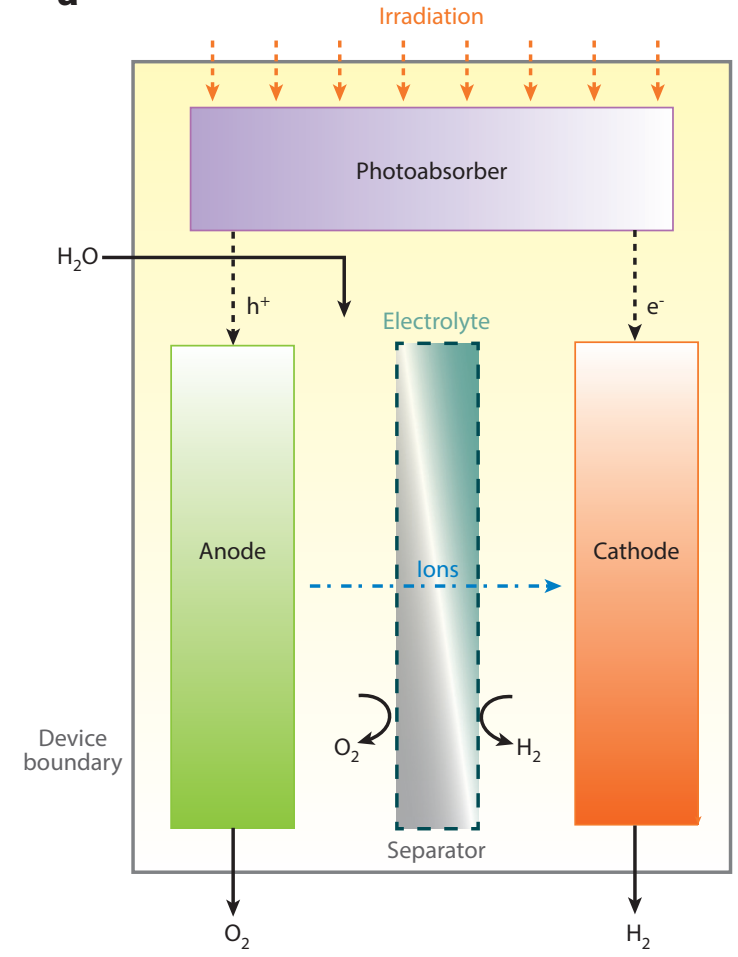

b

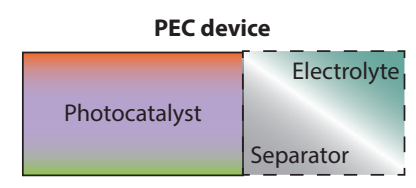

Figure 1

(a) Description of the physical processes occurring in a PEC solar-water-splitting device and (b) three major device configurations with different levels of component integration. Abbreviation: PEC, photoelectrochemical; PV, photovoltaic.

two different materials relaxes the material requirements and simultaneously allows for the protection of the photoabsorber, but at the expense of additional charge transport processes (and corresponding losses). Additionally, depending on the thickness of this protective layer, the semiconductor-liquid junction may be virtually suppressed, requiring an alternative method for charge separation, such as traditional solid-state semiconductor junctions (basic components in current photovoltaic technology), resulting in a so-called buried junction device type (4). The solid-liquid junctions show potential advantages over solid-solid junctions because the surface recombination and charge extraction can be altered by chemical reactions (39). Nevertheless, solid-state junctions are very efficient at charge separation.

Lastly, the externally wired PV plus electrolyzer device approach describes a group of devices in which the photoabsorber is not surrounded by the electrolyte but is physically separated from the reaction centers. In this case, the charge carriers can be transported over significant distances before arriving at the catalytic sites (e.g., through electrical wires). The catalytic sites are in direct contact with the electrolyte and carry out the water-splitting reactions. These device approaches provide pathways for an individual optimization of the components using power electronics for the coupling. Additionally, they provide the possibility for a very flexible device approach, as alternative renewable electricity (e.g., wind), according to availability and price, can be used to drive the electrolysis component. 
Figure 2

Schematic of the various physical phenomena and their coupling taking place in a photo-electrochemical (PEC) device. The arrows indicate the two-way coupling between the different physical phenomena owing to exchange of variables (e.g., velocities, temperatures) and material properties' dependence on different variables (e.g., temperature). The colors indicated correspond to the components in which each of the phenomena takes place, as depicted in Figure 1: photoabsorber (violet), catalysts (orange and green), ion conductor (grey and light blue), and educt delivery and product evacuation components (yellow).

\section{PHYSICAL PROCESSES OCCURRING IN PRACTICAL PHOTO-ELECTROCHEMICAL SOLAR-FUEL DEVICES}

The physical phenomena taking place in a PEC device (summarized above) are schematically shown in Figure 2 and can be described by electromagnetic wave propagation and radiation absorption, charge generation, charge transport (including transport across interfaces) and separation, electrochemical reactions (heterogeneous catalysis), mass transport and fluid flow (reactant transport, ionic transport, product separation), and heat transfer. These phenomena are strongly coupled, attesting to the complexity of modeling such devices.

\section{Electromagnetic Wave Propagation, Radiation Absorption, and Charge Generation}

The electromagnetic waves, i.e., the solar radiation, incident on a PEC device must be absorbed by the semiconductor material to provide energy to the device. The spectrum of the incident solar radiation resembles the spectrum of a black body radiating at 5,800 K, with approximately $25 \%$ of the energy incident at wavelengths below $500 \mathrm{~nm}$. PEC devices use photon-absorbing semiconductors, which generate electron-hole pairs upon irradiation by photons with energies larger than the band gap energy of the semiconductor.

The propagation of the electromagnetic wave toward and within the semiconductor material(s) is described by Maxwell's equations, in which the spectral absolute permittivity and the spectral permeability characterize the medium's influence on the electric and magnetic field (40). The electric and magnetic field describe the spectral, time-averaged energy density vector (the so-called Poynting vector) within the semiconductor. The spatial variation in the Poynting vector quantifies the absorbed energy, and the integration over all wavelengths provides the rate of the charge carrier pair density generation. Macroscopically, the absorption behavior of radiation in semiconductor materials can be simplified to the Beer-Lambert law (41), formally a solution to the Maxwell equations for planar layers of homogeneous media $(42,43)$. The change in intensity is described by an exponential decrease in the irradiation intensity, and the (spectral) absorption coefficient 
characterizes the typical absorption length. The Beer-Lambert law allows for a simpler and more straightforward calculation of the charge generation term but is unable to accurately quantify the absorbed radiation in nonplanar, nanometer- or micrometer-sized structured photoabsorbers.

\section{Charge Transport}

The generated charge carrier pairs (holes and electrons) will be transported within the semiconductor material encountering an electric field, concentration gradients, or temperature gradients. The distribution of the charge carriers must fulfill the charge conservation equations in which the change in carrier concentration is balanced by generation and recombination (e.g., radiative, Auger, or Shockley-Read-Hall recombination) and a transient term. The carrier distribution can be used to calculate the electric field and the potential in the semiconductor material.

The generated charge carrier pairs must be separated. In PEC processes using electrodes with dimensions larger than the typical space charge layer thickness, an electric field is the primary force for the charge separation. This electric field is induced at the solid-liquid interface (semiconductor-electrolyte), where the equilibration of the Fermi level and the solution redox potential in the semiconductor and electrolyte, respectively, results in band bending and subsequent development of a space charge layer. The electron-hole pairs will likely be separated if they are generated within the space charge layer, or if the typical distance to the space charge layer is smaller than the diffusion length. The separated minority carriers, i.e., electrons in p-type semiconductors or holes in n-type semiconductors, promote subsequent cathodic or anodic electrochemical processes at the interface if the conduction band is more negative than the oxidation reaction potential or the valence band is more positive than the reduction potential, respectively. If the carrier diffusion length is larger than the typical distance to the collector, the majority carriers are drawn toward the bulk of the semiconductor and are collected at the semiconductor-metal junctions (Schottky or Ohmic contacts), where they are provided to the counter electrode. The potential of the charge carriers at the counter electrode is the same as the Fermi level of the photoelectrode under photoexcitation. The dark counter electrode can be externally biased, or alternatively, a photoactive counter electrode can be used to ensure a matching potential level for the corresponding half-reaction.

For a semiconductor covered by a thick protection layer, the band bending of the semiconductor at the interface is not exhibited. Instead, traditional but buried solid-state junctions are usually introduced for the charge separation. Similarly, for the externally wired PV-plus-electrolyzer device approach, solid state junctions are usually incorporated in the PV. An exception to this is found in dye-sensitized solar cells, in which buried semiconductor-liquid junctions are used for charge separation (26).

\section{Interface and Electrochemical Reaction}

Most challenging for the charge transport investigations are the interface behavior and the characterization and quantification of the kinetic constants for the interfacial charge transfer. In PEC device configurations, the catalytic sites are at the semiconductor-liquid interface, and advanced theories on illuminated semiconductor-liquid interfaces are required to describe the interfacial chemistry and kinetics (44). For the simpler case when the semiconductor-liquid junction is decoupled from the catalytic site, we instead use a conductor with or as a catalyst to enhance the electrochemical reactions. These catalysts facilitate the electrochemical reaction by enhancing the surface kinetics. The traditional Butler-Volmer-type reaction current description can be used for metallic electrodes (45). Additionally, the catalysts are often metals, building an electron or 
hole trap while providing barriers for the recombination of the charge carrier and, consequently, enhancing the charge carrier separation.

\section{Mass Transport and Fluid Flow}

The electrochemical reaction at the interface provides a source term for species transport equations, such as ions or product species. The ions produced in the corresponding half reaction must be transported to the counter electrode, and the produced species (hydrogen and oxygen) must be separated and evacuated. The ion transport in liquid or polymeric electrolytes is usually described by the Nernst-Plank equation, which includes diffusion, convection, and migration terms (46). To minimize the transport losses, electrolytes with large conductivities and device designs that minimize ion transport path lengths are desired. The former is achieved by using highly acidic or basic liquid electrolytes, or by the addition of supporting electrolytes. Supporting electrolytes impose an additional challenge, namely, the buildup of supporting electrolyte ion concentration gradients, introducing additional, detrimental potential losses to a device. Engineering solutions can help to overcome some of these challenges (24). Short ion transport path lengths can be achieved by reducing the device size, e.g., by using microfluidic devices or micrometer-sized multifunctional membranes, such as nanowires embedded in polymeric electrolytes.

The products of the electrochemical reaction, e.g., oxygen and hydrogen, must be produced at spatially separated locations and separated by an ion-conducting and species-impermeable (diffusion and convection) component - the separator-in order to circumvent recombination reactions (lowering the product yield and efficiency) and prevent the buildup of an explosive product mixture. Separation also must be considered for products that are soluble in the electrolyte, which is often the case for PEC processes, as the operating current densities are small, comparable to the diffusion rate of dissolved species. Once local saturation or supersaturation of the solution is reached, the products will evolve in the gas phase, additionally influencing the reactor performance (e.g., scattering of the incident radiation, reduction of electrolyte conductivity, blocking of reaction sites, and introduction of convective streams). Nevertheless, the bubbles can be extracted from the system and, if this is done fast enough, can limit product crossover.

For the complete solution of the Nernst-Plank equation (including the convection term), a velocity vector field in the device will be needed, requiring the solution of the corresponding mass and momentum conservation equations $(47,48)$. This can introduce additional difficulties if the device is operated in a turbulence flow regime requiring turbulence modeling.

\section{Heat Transfer}

The resistive and magnetic losses in the photoabsorber, Joule heating in the conductors, and the reaction heat of the electrochemical reaction will contribute to a heat source term, which will be required for the solution of the energy conservation equation. Interestingly, the operating temperature will influence the performance of the photoabsorber, the electrochemical reaction, and the mass transfer in the device. These effects are inversely influenced by temperature and result in a tradeoff in performance.

The one-material device approach makes it difficult to gain from the positive temperature effect on the chemical reaction, as the photoabsorber is simultaneously also the catalyst, and consequently temperature separation for the different functions is not possible. For the device approaches with separated absorber materials and catalysts, smart temperature management can be used to profit from the enhanced semiconductor performance at lower temperatures and the enhanced reaction and mass transport at higher temperatures $(29,49)$. 


\section{DESIGN GUIDELINES FROM MULTIPHYSICS COMPUTATIONAL MODELS}

As for any other device design and engineering challenge, modeling can significantly support the design and optimization of the reactor at a reduced cost and faster pace. In addition to device design feasibility and optimization, modeling can provide guidelines for research and development of the material and components owing to the identification of performance bottlenecks and their association to specific components and operational conditions. Device modeling is also able to predict scale-up performance and can help in life cycle assessment and technoeconomic optimization.

The majority of simulation approaches to assess PEC performance and optimization are based on equivalent circuit models; i.e., the semiconductors are modeled by electrical diodes, and the internal electrolyzer is described by a load, which is a series of resistances resulting from the various overpotentials. Rocheleau et al. (50) introduced one of the first PEC engineering studies based on equivalent-circuit models. These types of models are still the standard nowadays and have been used to study the influence and choice of the catalysts or photoabsorber combinations on performance (51-54). Nevertheless, these models rely on equivalent circuits, requiring fitted or semiempirical component parameters, and consequently contribute little to a better understanding and design guidance of practical systems. Recently, one-dimensional $(55,56)$ and two-/threedimensional $(28,29,57,58)$ multiphysics models have been developed that solve for the governing coupled conservation equations in realistic reactor domains, allowing for a better understanding of the transport phenomena in the device and of the interactions between the properties of the components and the design choices of the system. A summary of general design guidelines is given here based on generalized designs modeled in References 28 and 29, in which aspects of kinetics, protecting layers, design and dimensions, separator properties, electrolyte properties, and operational conditions are discussed.

Device dimensions calculated based on the limitations imposed by the overpotential required in the device and the available photopotential showed that PEC devices require dimensions in the range of centimeters for practical devices operating in an electrolyte with equivalent ionic conductivity to $1 \mathrm{M}$ sulfuric acid, operational photocurrent densities of $20 \mathrm{~mA} / \mathrm{cm}^{2}$, and operational potential of approximately $1.7 \mathrm{~V}$. These limitations come mainly from the ion transport in the electrolyte (28).

Introduction of a device design with a catalytically separated and protected photoabsorber showed that the transparent, conducting protection layer can significantly increase the system performance, as it allows for the redistribution of the charge toward catalytic locations separated by shorter ionic path lengths. This enhanced performance relied on the conductivity of the layer, the surface roughness, and the kinetics of the catalysts. The latter two were shown to have an equivalent effect. In general, it is important to ensure that the rate of the reaction matches the transport rate of the carrier through the conducting layer to the reaction site and vice versa. The kinetics can also be increased by considering the surface roughness, i.e., the specific surface area. If the conducting protection layer is not catalytically active, the addition of a (photoabsorbing) catalyst on the protection layer is required only at the edges of the photoabsorber, effectively reducing the amount of catalyst and increasing the choice of materials to also include absorbing catalysts (28).

Efficiency calculations for catalytically separated and protected photoabsorber devices and externally wired PV/electrolyzer devices using DC-DC converters showed that their performance behaves differently during the day. Whereas the catalytically separated and protected photoabsorber device performed lowest during midday in a device limited by overpotential, the 
performance was highest during midday for a PV/electrolyzer device. And whereas the former device group suffered from higher overpotentials at larger irradiation, the latter device group used an individually optimized electrolyzer in addition to power electronics, allowing it to operate at constant electrolyzer efficiency. Nevertheless, PV/electrolyzer devices operated at much higher current densities, effectively reducing the electrolyzer efficiency and, correspondingly, potentially operating at lower efficiencies than the catalytically separated and protected photoabsorber devices. Additionally, catalytically separated and protected photoabsorber devices can derive benefits to performance at elevated temperatures, as increased temperatures have a beneficial effect on mass transport and chemistry, possibly outweighing negative effects on photoabsorber performance (29).

\section{PHYSICAL DEMONSTRATIONS OF SOLAR-FUEL DEVICES}

The subsections below describe the experimental advances in physical demonstrations of solarhydrogen generators based on the three device groups described above.

\section{Integrated Photo-Electrochemical Devices}

PEC devices are those devices in which the irradiation absorption and the electrochemical reactions are constrained to occur at the surface of photoabsorbers. For efficient solar-hydrogen conversion, these devices require the implementation of multiple absorbers that are able to supply enough photovoltage to drive the water-splitting reaction $(>1.23 \mathrm{~V})(52,59)$. The most widely studied materials for photocatalytic water oxidation are based on $\mathrm{TiO}_{2}(60-64)$, hematite $\left(\alpha-\mathrm{Fe}_{2} \mathrm{O}_{3}\right)(61,65-68)$, $\mathrm{WO}_{3}(26,54,69,70)$, and $\mathrm{BVO}_{4}(36,71-75)$. This set of oxide materials is capable of operating at moderate current densities (hundreds of $\mu \mathrm{A}$ to a few $\mathrm{mA} / \mathrm{cm}^{2}$ ) and tends to be stable toward photoinduced degradation in aqueous electrolytes. Often, cocatalysts with high activity are deposited in the surface of these photocatalysts to enhance the rates of the reactions. Materials systems that use cocatalysts to partially cover the surface of the semiconductor were also included within the PEC category in this review, as the semiconductor surface would still be partially exposed to the electrolyte and could participate in the electrochemical reactions. Although these systems were considered as PECs, it must be noted that their physics differ from systems based on semiconductors alone. In most systems that use cocatalysts, the charge carriers generated in the photoabsorber are transferred to the catalysts via a semiconductor-metal junction, as opposed to semiconductoronly PEC materials in which charge transfer happens across the semiconductor-liquid junction. Spontaneous solar water-splitting systems have been fabricated using these oxide materials in conjunction with a second absorber. Abdi et al. (36) fabricated devices using gradient doping of $\mathrm{BVO}_{4}$ to enhance the charge separation in the photoanode and were able to achieve current densities that reached over $4 \mathrm{~mA} / \mathrm{cm}^{2}$ and potentials below $2 \mathrm{~V}$. In these $\mathrm{BVO}_{4}$-based devices, the additional photovoltage was generated using a tandem-junction a-Si cell that was not in contact with the electrolyte, and the oxygen evolution catalytic rate was greatly enhanced by the use of CoPi cocatalysts. Brillet et al. (26) demonstrated dual-absorber systems based on both $\mathrm{WO}_{3}$ and hematite integrated with dye-sensitized solar cells that reached solar-to-hydrogen (STH) efficiencies of up to $3.1 \%$. Shaner et al. (54) demonstrated micrometer-sized structured tandem-junction systems (i.e., tandem $\mathrm{WO}_{3} / \mathrm{Si}$ microwires), which can enhance both the light-absorption via trapping mechanisms as well as the catalytic rates via an increase in active surface area. Despite these past efforts to further improve the performance characteristics of these photoanodes, their practical implementation is hindered by their low demonstrated efficiencies, which lie below 5\% STH efficiency. 


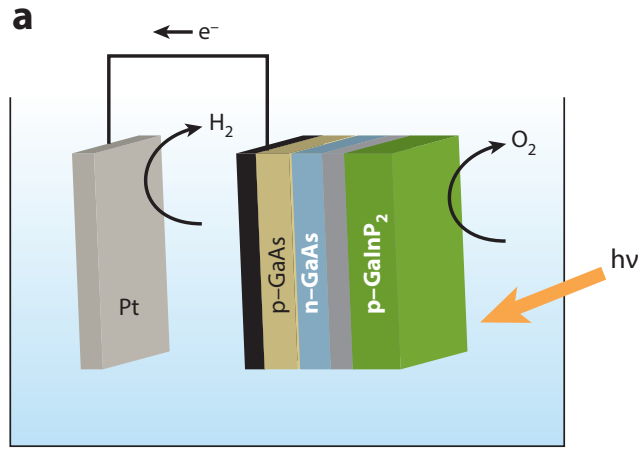

b
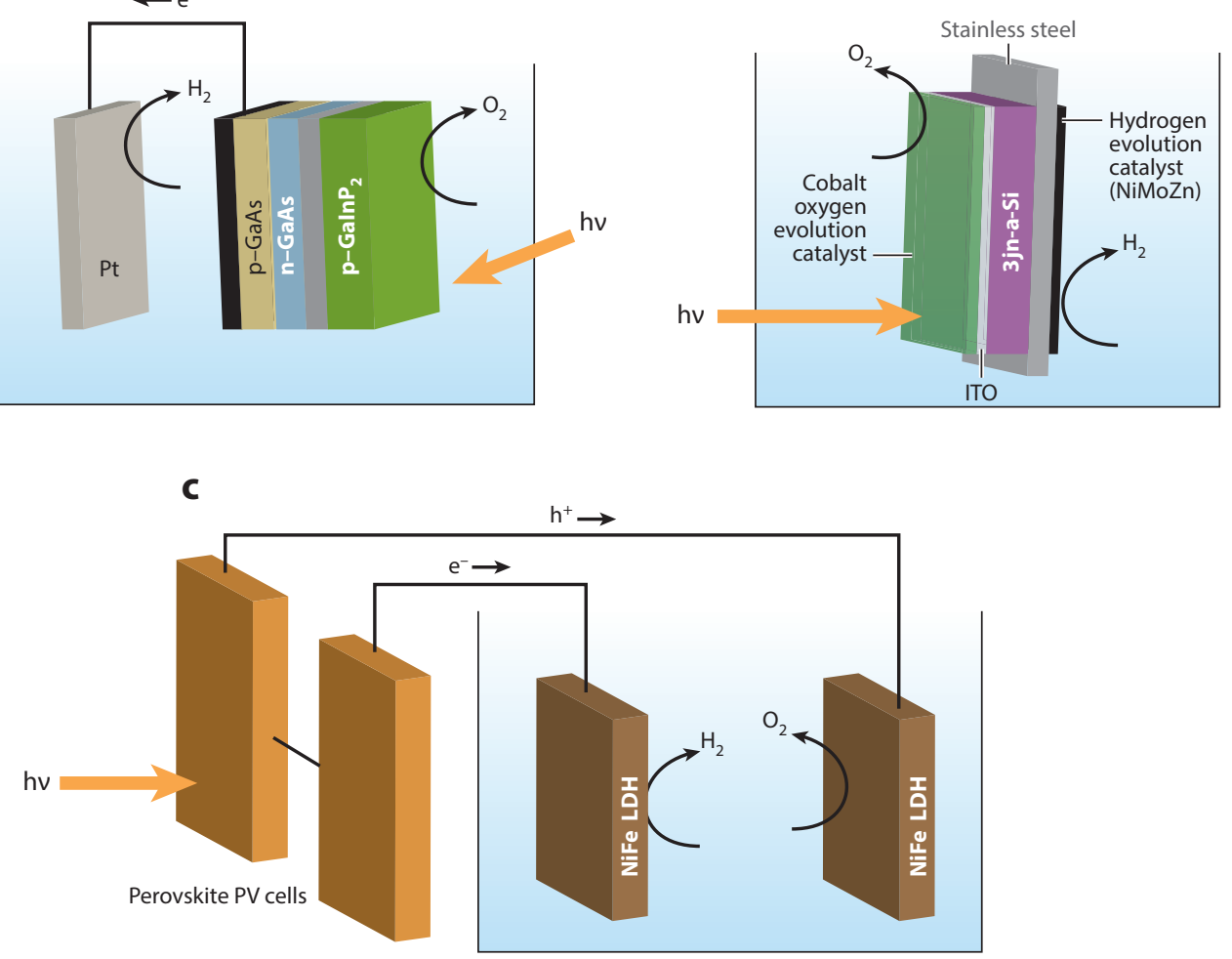

Figure 3

Examples of solar water-splitting material systems with different degrees of integration. The system reproduced in $a$ corresponds to a tandem cell based on III-V semiconductor materials used as photocatalysts (17). $b$ shows an integrated system where catalysts are used together with multijunction amorphous silicon cells to drive the water-splitting process (25). The wired system described in $c$ corresponds to a device that can operate at solar-to-hydrogen efficiencies as high as $12.3 \%$ by using perovskite photovoltaic cells together with earth-abundant catalysts (92).

\section{Protected Photoabsorber Devices}

An alternative method to the implementation of the metal oxides described above is to use photoabsorber materials with superior absorption and electronic properties together with electrocatalysts to carry out the water-splitting process. Common materials used for solar water splitting involve high-performant III-V semiconductors and earth-abundant and widely deployed Si-based absorbers (Figure 3a,b). Early attempts at developing devices based on these materials are characterized by fairly high efficiencies but also fast materials degradation. Khaselev et al. $(17,76)$ demonstrated cells based on $\mathrm{GaInP}_{2} / \mathrm{GaAs}$ tandem cells with efficiencies exceeding $12 \% \mathrm{STH}$ efficiencies. In these systems, the water oxidation reaction takes place directly at the surface of the semiconductors at the expense of the degradation of the semiconductor. Si-based systems, in combination with cocatalysts, can lead to devices with modest efficiencies (approaching 10\% STH efficiency) $(24,25,31,33,77-79)$. Achieving long-term stability in both Si-based and III-V semiconductor photoelectrodes is crucial for their practical implementation in solar-hydrogenprocessing devices. One approach to enhancing stability and long-term performance is to operate devices at moderate $\mathrm{pH}$ regimes under buffered electrolytes $(24,80)$ where some materials can 
stably operate (25). Nocera et al. $(25,31,51,53)$ pioneered the development of Si-based systems that operate stably in buffered solutions for several hours and implemented earth-abundant catalysts that led to up to $4.7 \%$ STH efficiencies. Passive systems (where no convection is present) that operate under buffered electrolytes suffer from significant performance degradation as $\mathrm{pH}$ gradients form around the electrodes $(80,81)$, but careful engineering of the reactor and the use of convective streams can allow systems to operate continuously under these conditions. This can be achieved by the introduction of convection-driven recirculation streams across reaction sites, which can help prevent the formation of undesirable concentration gradients that would otherwise form in passive systems (24). Concentration boundary layers near the electrode surface are unavoidable but manageable by internal convection in the reactor, in particular for electrolytes at moderate $\mathrm{pH}$ in mildly acidic or basic regions (82). An alternative approach is to develop surface protection coatings that are intrinsically stable under strong acidic or basic electrolytes where local concentration gradients would be small and their effects in the device performance negligible. Such protection layers must (a) efficiently transfer charges from the semiconductor to the catalytic centers, $(b)$ allow light to be absorbed efficiently by the semiconductor, and (c) operate robustly under the electrolyte that they are intended for. Moreover, the device architecture will need to be considered when designing such protective layers (29). In general, devices inherently perform better if light does not need to travel through the electrolyte before it reaches the semiconductor (83). Absorption losses in the electrolyte, scattering owing to the bubbles generated at the surfaces, and parasitic absorption losses in the cocatalysts can prevent the photoabsorber from receiving optimal amounts of illumination. In the case that the semiconductor is illuminated directly, or through a transparent support (e.g., glass), the protective coating must also serve as a reflector, in which case a thick metallic coating could serve as a protective layer for the semiconductor, and be able to conduct charges directly to the catalyst. For cases in which the light is irradiated from the electrolyte side, the protective layer must be transparent in the absorption window of the semiconductor. In some instances, it might be advantageous to irradiate light from the semiconductor-liquid interface side so that the minority carriers can be harvested more efficiently. Some recent work has focused on using thin transparent layers of crystalline $\mathrm{TiO}_{2}$ to protect semiconductor surfaces, which has led to the development of Si-based photocathodes with stability in the order of $100 \mathrm{~h}$ (77). Thin layers of $\mathrm{TiO}_{2}$ are needed owing to the poor charge mobility in this material. Only recently, $\mathrm{Hu}$ et al. (84) described a method in which, by using amorphous $\mathrm{TiO}_{2}$, thick protective layers can be used, at the same time allowing sufficient hole mobility to support the water oxidation reaction and robustly passivating the semiconductor surfaces. The advances in protective layers for solar-fuel generation are encouraging and are expected to lead to practical demonstration devices where the light-absorber unit is submerged in the electrolyte.

\section{Photovoltaics-Driven Electrolysis Devices}

The previous subsections focused on the challenges associated with systems where the electrochemical reactions take place in the same physical location as (or in very close proximity to) the photoabsorption units. As discussed above, this creates significant semiconductor stability challenges because the photoabsorbers must be surrounded by the electrolyte. A simpler alternative that is achievable with currently available devices is to couple photovoltaic components with electrocatalysts in physically separated locations by using current conductors (i.e., wires). These devices can be designed for optimal solar-hydrogen generation based on the output from the PV and the load posed by the electrolysis units (imposed by the electrocatalysts, concentration overpotentials, and ohmic losses in the electrolyte). Such analyses can be used to design optimal reactors in terms of efficiency, cost, and energy requirements $(51,56,85)$. These devices pose 
several advantages with respect to the devices discussed previously: (a) The dimensions of the PV and electrolysis components can be optimized independently; (b) enhanced stability of PV components can be obtained, as they are not in contact with the electrolyte; $(c)$ path lengths for ion diffusion can be shortened between reaction sites, as the semiconductor is not placed in between electrocatalysts; $(d)$ simple integration of different PV technologies can be achieved, as multiple cells can be connected in series to achieve the desired voltage output; (e) there exists the possibility of incorporating current converters (either DC/DC or AC/DC) to extract the maximum power of the PVs at all irradiation levels; and $(f)$ there is the possibility of grid integration, which would allow the sunlight collection to occur where it is most advantageous and the hydrogen production to take place where it is needed, possibly using other energy sources during low irradiation times for hydrogen production.

Laboratory-scale demonstrations of these systems have achieved remarkable performances. Systems based on III-V semiconductors have been developed and show efficiencies up to $18 \%$ STH using concentrated solar irradiation $(19,35)$, whereas systems based on Si PV cells have achieved efficiencies above 10\% (86-90, 91). More recently, solution-processed perovskite-based PV components together with earth-abundant electrocatalysts have been used to drive the watersplitting reaction at high efficiency levels, up to $12.3 \%$ STH (92) (Figure 3c). Despite the decoupling of the light-absorption and water-splitting components in these systems, integration at the systems level, such as thermal management, could be beneficial and result in improvements in efficiency by cooling the photovoltaics while preheating the water feed to the electrolyzer $(35,49)$. $\mathrm{PV}$-electrolysis systems are still the closest to a market alternative for solar-hydrogen production, and pilot-scale projects based on this concept are on their way (93).

\section{DESIGN GUIDELINES FROM LIFE CYCLE ASSESSMENT AND TECHNOECONOMICS}

Although the previous subsections describe in detail the technical and scientific aspects associated with the design of integrated solar-fuel devices, it is also important to consider practical aspects associated with viability for the deployment of this technology. At the heart of these aspects lies life cycle assessment and technoeconomic considerations. At a minimum, solar-fuel devices must harvest more energy than the energy required for their fabrication and device operation. At the same time, practical deployment of solar-fuel devices requires systems to be designed in such a way that fuel production cost is minimized. These energy and cost considerations ought to be critical in the way practical devices are fabricated, as they directly impact the feasibility of the implementation of the technology. Several factors impact the cost of hydrogen production as well as the energy balance of the systems, including materials selection, manufacturing techniques, device and plant design, geographic location, device efficiency, systems lifetime, and properties of the output product. Gaining an understanding of the extent to which each of these factors can affect the system energy balance and hydrogen production cost is critical for developing design rules for practical devices. Only a few experimental attempts have been made to include scale-up considerations for solar-fuels technology at the research and development level $(30,94)$, and less than a handful of studies have focused on the technoeconomic $(20,85,95,96)$ or life cycle $(97$, 98, 99; M. Dumortier \& S. Haussener, manuscript in preparation) assessment of the technology.

Early attempts at estimating the economic viability of solar-fuel generators date back to 1985 (96), when different designs based on planar arrays of PEC solar-hydrogen generators as well as tubular designs with parabolic concentrators were considered. Results from this study estimated that hydrogen production prices from PEC cells could reach values of $\$ 11.5-19.0 / \mathrm{kg}_{\mathrm{H} 2}$ for flat 
panel designs and $\$ 31.8-47.8 / \mathrm{kg}_{\mathrm{H} 2}$ for concentrator designs. ${ }^{1}$ More recent studies have estimated hydrogen production prices for similar systems at significantly lower levels, between $\$ 4.00 / \mathrm{kg}_{\mathrm{H} 2}$ and $\$ 10.40 / \mathrm{kg}_{\mathrm{H} 2}$ for concentrated and nonconcentrated systems, respectively (20). The recent lower price estimations are mostly due to significant cost reduction in semiconductor materials for radiation absorption, but despite the differences, both of these technoeconomic analyses of integrated PEC systems indicate that efficiency is the single most important factor that can help to decrease overall hydrogen production cost. This conclusion arises from the fact that the PEC balance of systems dominates the cost structure, and if their active PEC components are capable of generating larger amounts of product fuel, their cost can be reduced. The technoeconomic analyses referred to above focused on particular geometries and plant designs and the use of integrated PEC units in which the water-splitting reactions are conducted at the surface of the radiation absorber components. Alternatively, the problem of cost-effective PEC solar-hydrogen generation can be treated in a generalized manner, where all the components are allowed to vary in dimensions and composition and their arrangement is optimized to minimize the hydrogen production cost. Recent attempts at such analysis have concluded that further savings are attainable by not confining the dimensions of the water-splitting components from the light absorption ones, which could potentially lead to hydrogen production prices below $\$ 3 / \mathrm{kg}_{\mathrm{H} 2}$ (after accounting for compression, storage, and distribution costs) (85). The additional cost savings in these systems arise from the geometrical optimization of the devices composed of electrically integrated Si-based PVs and membrane-electrode assembly (MEA) electrolyzers. Optimized devices are estimated to be composed of small electrolysis reactors, while sunlight is collected over PVs spanning large areas (over two orders of magnitude larger). Under this configuration, the radiation absorber component accounts for the great majority of the systems cost (up to 96\%), and improvements in efficiency, cell cost, and operation under concentrated sunlight can further help to reduce the cost.

In addition to economic viability of solar-hydrogen devices, the technology must be able to produce more energy over its lifetime than what is required for its manufacturing and operation. LCA of the energy balance of solar-hydrogen devices has only recently been performed for PECbased devices (97) and large-scale (1-GW) hydrogen production plants (99). It must be noted that significant challenges arise when performing LCA studies of these early-stage technologies, as there are many uncertainties regarding the performance and behavior of materials. These studies indicate that for devices operating at $10 \%$ STH efficiencies, after accounting for the infrastructure required in a hydrogen production plant, the energy payback time for the system is estimated at slightly over eight years. They also show that significant gains can be achieved by increasing the efficiency of the devices and their lifetimes, whereas improvements in factors related to the balance of systems have a minor effect on the energy balance of the hydrogen production systems. Although these analyses are based on assumptions made regarding the form factor and general working principles of PEC-based solar-hydrogen-production facilities, they provide important guidelines for design and performance targets.

\section{OUTLOOK AND IMPLEMENTATION ASPECTS FOR PHOTO-ELECTROCHEMICAL SOLAR-HYDROGEN DEVICES}

Although solar-fuel technologies have been under development for more than four decades, their implementation is still in its very early stages. For the community to accelerate progress on solarhydrogen generators, a pragmatic and unbiased evaluation of the current device design space and

${ }^{1}$ Cost values are reported in 2014 USD, after accounting for inflation. 
Table 1 Challenges and advantages for the introduced device groups with different levels of component integration ${ }^{\mathrm{a}}$

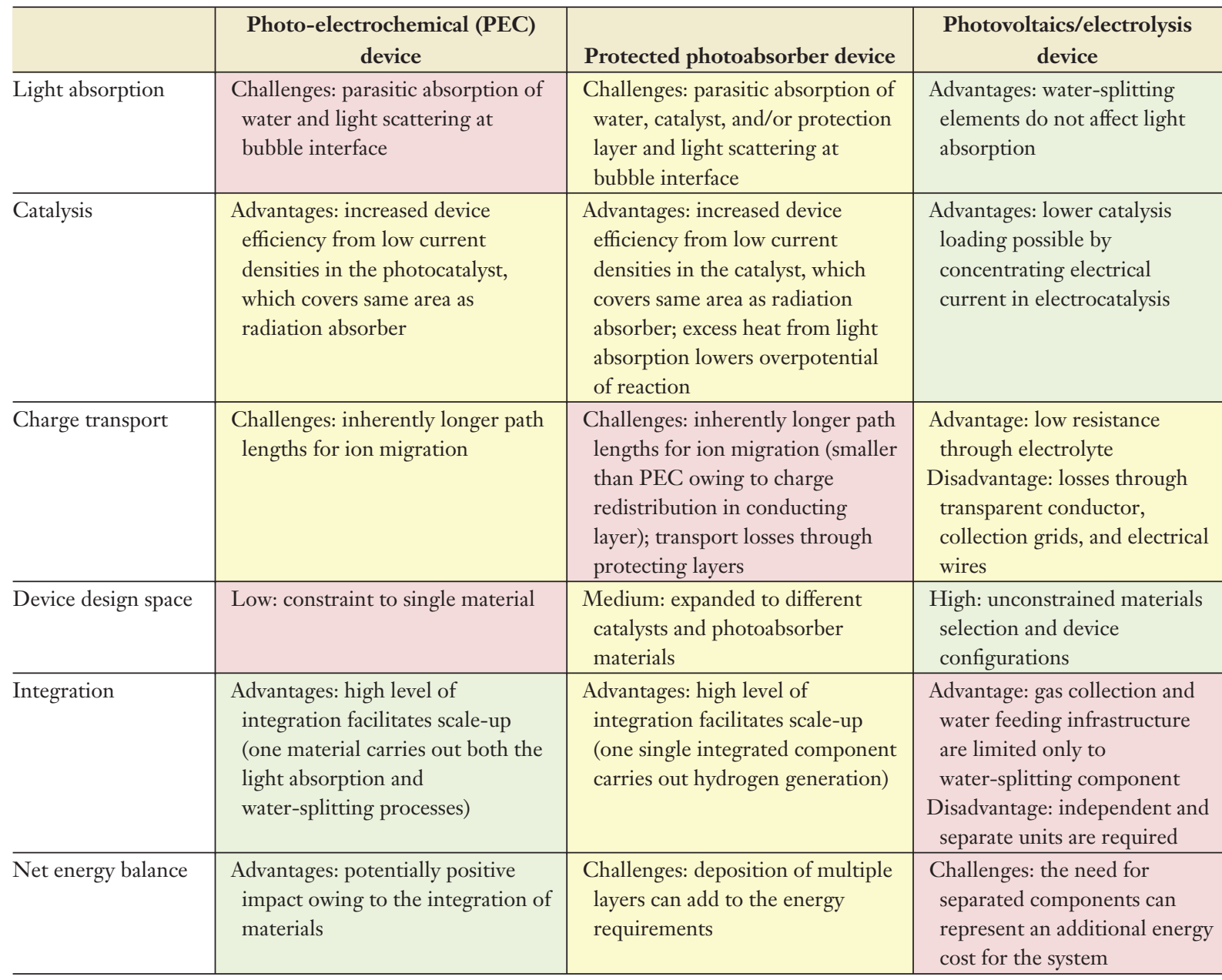

aThe background in the table is colored in green for highly favorable scenarios, in yellow for moderately favorable conditions, and in red for significant implementation challenges.

of state-of-the-art device components is needed. Common desirable features of devices, such as the use of earth-abundant components, high efficiencies, and high levels of integration, must be placed in the context of technological viability while keeping in mind various implementation constraints (i.e., production scale, operating conditions, competitive cost levels for hydrogen).

In terms of device design, there are fundamental differences between the three major approaches analyzed in this review, each exhibiting a different level of integration: PEC, protected photoabsorber, and PV/electrolysis devices. Table 1 summarizes some of the advantages and challenges that each of these approaches pose regarding their practical implementation. Note that currently there are no PEC material systems that can reach practical performance levels. Catalytically separated and protected photoabsorber devices based on silicon absorbers could potentially be deployed $(24,25,31,33)$, although recent attempts have failed to commercialize the technology (100). PV/electrolysis systems based on Si PVs and state-of-the-art electrolyzers are certainly the 
closest to a market solution for solar-hydrogen generation. The dramatic decrease of prices of PV in the past decade $(101,102)$ and advances in electrolysis systems show the potential for these technologies to finally be deployed. One of the main advantages that PV/electrolysis devices present is their modularity and flexibility in terms of systems design and implementation. PV/electrolysis devices need not have components of equal dimensions; rather, their dimensions can be optimized to obtain the optimal costs for hydrogen production. Furthermore, the implementation of current invertors and integration into the grid allows the radiation absorption and hydrogen generation units to operate in physically distant places (such that the radiation absorption occurs in areas with large solar irradiation and hydrogen production close to hydrogen fueling stations). The grid integration and distributed operation of solar-hydrogen systems can also bring significant advantages, as hydrogen transportation costs can be minimized, electrolyzers can operate with electricity from mixed sources even when there is no sunlight, and arbitrage gains in the electricity market can be exploited if the hydrogen is used to generate electricity with fuel cells. All these advantages suggest that efficiently operating PV/electrolysis devices could allow the deployment of solar-hydrogen devices in the near term. Competitive PEC or catalytically separated and protected photoabsorber devices will need at the very least to be manufactured using materials (including the balance of systems) with intrinsically lower costs than current Si PV technologies. Extracting charges to directly perform the water-splitting reactions will also need to be more efficient than extracting the charges in the form of electricity and using them in stand-alone electrolyzers. These two conditions will need to be satisfied even if the materials systems are to be operated inside electrolytes, as required by the device designs. This review does not evaluate other promising alternatives, such as particle or molecular-based solar-hydrogen systems, which promise to bring significant cost advantages, but are in much earlier stages of development (20).

As noted in Table 1, the three different approaches have different advantages and challenges. In the case of PEC devices, materials with high efficiencies, high stability, and low cost do not exist currently, and this represents the most important challenge for those devices. In the case of protected photoabsorber devices, significant progress has been made in the development of robust materials that can withstand electrochemical processes under electrolytes, and long-term stability of protected radiation absorbers in continuously operating devices is likely to be achieved in the near future. Large efforts to discover material systems with appropriate properties can result in new sets of practical and deployable components that can be incorporated into practical devices. Combinatorial approaches to identify promising materials as both photoabsorbers and electrocatalysts have already started to show some promising directions for materials development (103-106). Transport challenges identified for the three device configurations referred to above can be tackled mostly by device design. As PEC and protected photoabsorber devices would face longer path lengths for ions to migrate between reaction sites, the design of their architecture and dimensions is critical for good device performance. In the case of these devices, micrometer-sized structured architectures would be preferred to reduce ionic transport losses. Several approaches have been proposed to overcome the transport limitations, including microwires-based systems (54, 78, 107-110) (Figure 4a), microfluidic systems $(111,112)$ (Figure $4 b$ ), and devices where photocatalytic particles are incorporated in MEAs as part of the catalyst layer $(113,114)$. Issues regarding multiphase phenomena are often overlooked in the community but can be central to obtaining devices that function efficiently in a continuous fashion. Bubble formation at the surface of reaction sites can affect device performance by reducing the active area for catalysis and, in the case of PECs or protected photoabsorber devices, can also affect the radiation absorption at the semiconductor owing to scattering at the gas-liquid interface. One novel approach to avoid the formation of bubbles involves the operation of devices with water vapor. In this way, all of the electrochemical processes can be carried out in a solid electrolyte, and both water inputs and gas outputs are confined to the vapor phase. 
a

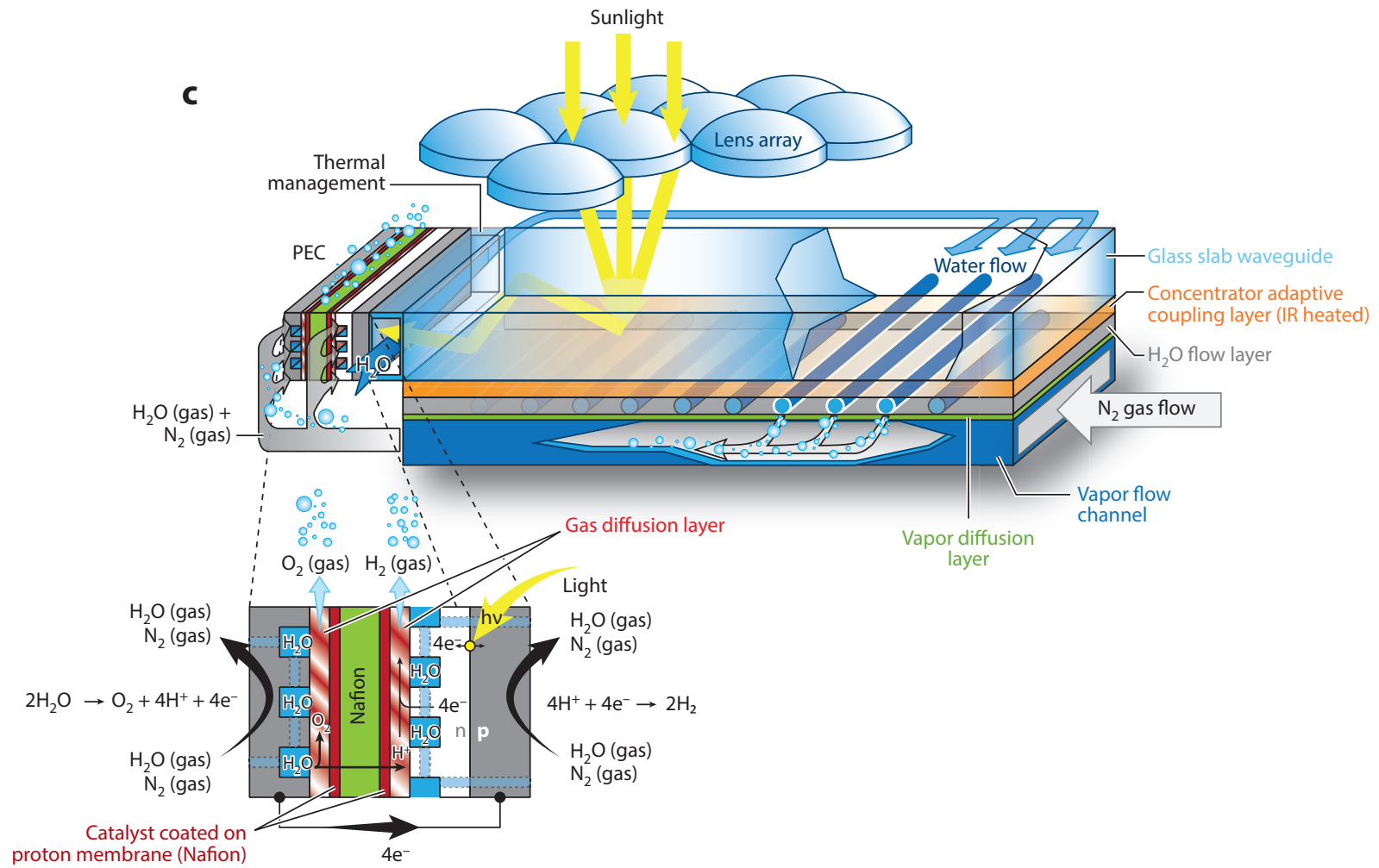

Figure 4

New concepts for integrated solar-hydrogen generators. (a) A membrane-embedded photocatalytic microwire array (107). These systems could benefit from light trapping within the microwire structures while allowing ion transport through the membrane and keeping the evolved gases separated. Microfluidic systems such as the ones described in $b$ can take advantage of short path lengths for ion transport and easy incorporation of components via standard microfabrication techniques. The complex system described in $c$ shows several approaches that can be used to improve solar-hydrogen generators: a self-tracking solar concentrator that can be used to reduce materials utilization and improve efficiency (119), heat management schemes that can be implemented to reuse heat to prepare the water feed prior to electrolysis (123), and water-splitting systems using water vapor as the feed (image courtesy of Volker Zagolla, SHINE project, EPFL). Abbreviation: PEC: photo-electrochemical. 
These devices are in the early stage of development, but guidelines for their fabrications have been drawn from modeling studies $(58,115)$, and experimental operation of MEA electrolyzers on the vapor phase has been demonstrated (116). Also, proper thermal management in devices can allow systems to operate continuously at higher levels of efficiency. These thermal management schemes can be effectively harnessed in catalytically separated and protected photoabsorber devices, where the excess heat from the light-absorption process can be used to enhance the rate of the catalytic processes $(29,117)$. Lastly, radiation management techniques can potentially be used to enhance the radiation absorption in the semiconductor material and increase the STH efficiency (118-122). These techniques can reduce the use of materials by concentrating the light into the photoactive units of devices, which could result in cost savings for device fabrication. A graphic description of a device design that takes advantage of both light and heat management is presented in Figure $4 \boldsymbol{c}$.

The demonstration and deployment of practical, efficient, stable, sustainable, and inexpensive PEC solar-hydrogen generators relies on investigations of complete PEC device designs, establishment of modeling-based design guidelines, and assessment of LCA and technoeconomics. Focusing the research efforts on single-material development that overlooks the interactions of components in a complete working design risks delaying the implementation of the technology. Shifting the focus toward the implementation and fabrication of integrated PEC solar-hydrogen devices could accelerate the conception of practical solutions for the current pressing energy and environmental needs of society.

\section{DISCLOSURE STATEMENT}

The authors are not aware of any affiliations, memberships, funding, or financial holdings that might be perceived as affecting the objectivity of this review.

\section{ACKNOWLEDGMENTS}

The authors would like to acknowledge the financial support of the Nano-Tera.ch initiative, as part of the Solar Hydrogen Integrated Nano Electrolysis project (Grant \# 530 101).

\section{LITERATURE CITED}

1. Lewis NS. 2007. Powering the planet. MRS Bull. 32:808-20

2. Romero M, Steinfeld A. 2012. Concentrating solar thermal power and thermochemical fuels. Energy Environ. Sci. 5:9234-45

3. Lipinski W, Davidson JH, Haussener S, Klausner JF, Mehdizadeh AM, et al. 2013. Review of heat transfer research for solar thermochemical applications. F. Thermal Sci. Eng. Appl. 5:021005

4. Walter MG, Warren EL, McKone JR, Boettcher SW, Mi Q, et al. 2010. Solar water splitting cells. Chem. Rev. 110:6446-73

5. Rongé J, Bosserez T, Martel D, Nervi C, Boarino L, et al. 2014. Monolithic cells for solar fuels. Chem. Soc. Rev. 43:7963-81

6. Maeda K, Domen K. 2010. Photocatalytic water splitting: recent progress and future challenges. F. Phys. Chem. Lett. 1(18):2655-61

7. Hisatomi T, Kubota J, Domen K. 2014. Recent advances in semiconductors for photocatalytic and photoelectrochemical water splitting. Chem. Soc. Rev. 43:7520-35

8. Piatkowski N, Wieckert C, Weimer AW, Steinfeld A. 2011. Solar-driven gasification of carbonaceous feedstock-a review. Energy Environ. Sci. 4:73-82

9. Nzihou A, Flamant G, Stanmore B. 2012. Synthetic fuels from biomass using concentrated solar energya review. Energy 42(1):121-31 
10. Blankenship RE, Tiede DM, Barber J, Brudvig GW, Fleming G, et al. 2011. Comparing photosynthetic and photovoltaic efficiencies and recognizing the potential for improvement. Science 332(6031):805-9

11. Chu S, Majumdar A. 2012. Opportunities and challenges for a sustainable energy future. Nature 488(7411):294-303

12. Lewis N, Nocera D. 2006. Powering the planet: chemical challenges in solar energy utilization. PNAS 103:15729-35

13. Newman J, Hoertz PG, Bonino CA, Trainham JA. 2012. Review: an economic perspective on liquid solar fuels. 7. Electrochem. Soc. 159:A1722-29

14. Turner JA. 1999. A realizable renewable energy future. Science 285(5428):687-89

15. Chueh WC, Falter C, Abbott M, Scipio D, Furler P, et al. 2010. High-flux solar-driven thermochemical dissociation of $\mathrm{CO}_{2}$ and $\mathrm{H}_{2} \mathrm{O}$ using nonstoichiometric ceria. Science 330(6012):1797-801

16. Furler P, Scheffe J, Gorbar M, Moes L, Vogt U, Steinfeld A. 2012. Solar thermochemical $\mathrm{CO}_{2}$ splitting utilizing a reticulated porous ceria redox system. Energy Fuels 26(11):7051-59

17. Khaselev O, Turner JA. 1998. A monolithic photovoltaic-photoelectrochemical device for hydrogen production via water splitting. Science 280(5362):425-27

18. Licht S, Wang B, Mukerji S, Soga T, Umeno M, Tributsch H. 2000. Efficient solar water splitting, exemplified by $\mathrm{RuO}_{2}$-catalyzed AlGaAs/Si photoelectrolysis. 7. Phys. Chem. B 104(38):8920-24

19. Peharz G, Dimroth F, Wittstadt U. 2007. Solar hydrogen production by water splitting with a conversion efficiency of 18\%. Int. F. Hydrogen Energy 32(15):3248-52

20. Pinaud BA, Benck JD, Seitz LC, Forman AJ, Chen Z, et al. 2013. Technical and economic feasibility of centralized facilities for solar hydrogen production via photocatalysis and photoelectrochemistry. Energy Environ. Sci. 6:1983-2002

21. James BD, Baum GN, Perez J, Baum KN. 2009. Technoeconomic analysis of photoelectrochemical (PEC) bydrogen production. Tech. Rep., Dir. Technol. Inc., Arlington, VA

22. Kromer M, Roth K, Takata R, Chin P. 2011. Support for cost analyses on solar-driven bigh temperature thermochemical water-splitting cycles. Tech. Rep., TIAX LLC, Lexington, MA

23. Villasmil W, Brkic M, Wuillemin D, Meier A, Steinfeld A. 2013. Pilot scale demonstration of a 100-kW th solar thermochemical plant for the thermal dissociation of ZnO. F. Solar Energy Eng. 136(1):011017

24. Modestino MA, Walczak KA, Berger A, Evans CM, Haussener S, et al. 2014. Robust production of purified $\mathrm{H}_{2}$ in a stable, self-regulating, and continuously operating solar fuel generator. Energy Environ. Sci. 7:297-301

25. Reece SY, Hamel JA, Sung K, Jarvi TD, Esswein AJ, et al. 2011. Wireless solar water splitting using silicon-based semiconductors and earth-abundant catalysts. Science 334(6056):645-48

26. Brillet J, Yum J-H, Cornuz M, Hisatomi T, Solarska R, et al. 2012. Highly efficient water splitting by a dual-absorber tandem cell. Nat. Photon 6(12):824-28

27. Dotan H, Kfir O, Sharlin E, Blank O, Gross M, et al. 2013. Resonant light trapping in ultrathin films for water splitting. Nat. Mater. 12(2):158-64

28. Haussener S, Xiang C, Spurgeon JM, Ardo S, Lewis NS, Weber AZ. 2012. Modeling, simulation, and design criteria for photoelectrochemical water-splitting systems. Energy Environ. Sci. 5:9922-35

29. Haussener S, Hu S, Xiang C, Weber AZ, Lewis N. 2013. Simulations of the irradiation and temperature dependence of the efficiency of tandem photoelectrochemical water-splitting systems. Energy Environ. Sci. 6:3605-18

30. Lewis N. 2013. An integrated, systems approach to the development of solar fuel generators. ECS Interface 22:43-50

31. Nocera D. 2012. The artificial leaf. Acc. Chem. Res. 45:767-76

32. Turner JA. 2004. Sustainable hydrogen production. Science 305(5686):972-74

33. Rocheleau RE, Miller EL, Misra A. 1998. High-efficiency photoelectrochemical hydrogen production using multijunction amorphous silicon photoelectrodes. Energy Fuels 12(1):3-10

34. Jacobsson TJ, Fjällström V, Sahlberg M, Edoff M, Edvinsson T. 2013. A monolithic device for solar water splitting based on series interconnected thin film absorbers reaching over 10\% solar-to-hydrogen efficiency. Energy Environ. Sci. 6:3676-83 
35. Rau S, Vierrath S, Ohlmann J, Fallisch A, Lackner D, et al. 2014. Highly efficient solar hydrogen generation-an integrated concept joining III-V solar cells with PEM electrolysis cells. Energy Technol. 2(1):43-53

36. Abdi FF, Han L, Smets AHM, Zeman M, Dam B, van de Krol R. 2013. Efficient solar water splitting by enhanced charge separation in a bismuth vanadate-silicon tandem photoelectrode. Nat. Commun. 4:2195

37. Jacobsson JT, Fjällström V, Edoff M, Edvinsson T. 2014. Sustainable solar hydrogen production: from photoelectrochemical cells to PV-electrolyzers and back again. Energy Environ. Sci. 7:2056-70

38. van de Krol R, Graetzel M, eds. 2013. Photoelectrochemical Hydrogen Production. New York: Springer

39. Sivula K. 2013. Solar-to-chemical energy conversion with photoelectrochemical tandem cells. CHIMIA Int. F. Chem. 67(3):155-61

40. Bohren C, Huffman D. 2004. Absorption and Scattering of Light by Small Particles. New York: John Wiley \& Sons

41. Modest M. 2003. Radiative Heat Transfer. Waltham, MA: Academic

42. Mishchenko MI. 2008. Multiple scattering, radiative transfer, and weak localization in discrete random media: unified microphysical approach. Rev. Geophys. 46(2):RG2003

43. Mishchenko MI, Tishkovets VP, Travis LD, Cairns B, Dlugach JM, et al. 2011. Electromagnetic scattering by a morphologically complex object: fundamental concepts and common misconceptions. F. Quant. Spectrosc. Radiat. Transf. 112(4):671-92

44. Nozik AJ, Memming R. 1996. Physical chemistry of semiconductor-liquid interfaces. F. Phys. Chem. 100(31):13061-78

45. Bard AJ, Faulkner LR. 2000. Electrochemical Methods: Fundamentals and Applications. New York: John Wiley \& Sons. 2nd ed.

46. Newman J, Thomas-Alyea K. 2004. Electrochemical Systems. New York: John Wiley \& Sons

47. Patankar S. 1980. Numerical Heat Transfer and Fluid Flow. New York: McGraw-Hill Inc.

48. Ferziger JH, Peric M. 2001. Computational Methods for Fluid Dynamics. New York: Springer-Verlag

49. Tembhurne S, Dumortier M, Haussener S. 2014. Heat transfer modeling in integrated photoelectrochemical hydrogen generators using concentrated irradiation. In Proc. 15th Int. Heat Transf. Conf., Aug. 10-15, Kyoto, 7pn.

50. Rocheleau RE, Miller EL. 1997. Photoelectrochemical production of hydrogen: engineering loss analysis. Int. 7. Hydrogen Energy 22:771-82

51. Winkler MT, Cox CR, Nocera DG, Buonassisi T. 2013. Modeling integrated photovoltaicelectrochemical devices using steady-state equivalent circuits. PNAS 110(12):E1076-82

52. Hu S, Xiang C, Haussener S, Berger AD, Lewis NS. 2013. An analysis of the optimal band gaps of light absorbers in integrated tandem photoelectrochemical water-splitting systems. Energy Environ. Sci. 6:2984-93

53. Surendranath Y, Bediako DK, Nocera DG. 2012. Interplay of oxygen-evolution kinetics and photovoltaic power curves on the construction of artificial leaves. PNAS 109:15617

54. Shaner MR, Fountaine KT, Ardo S, Coridan RH, Atwater HA, Lewis NS. 2014. Photoelectrochemistry of core-shell tandem junction $\mathrm{n}-\mathrm{p}+-\mathrm{Si} / \mathrm{n}-\mathrm{WO}_{3}$ microwire array photoelectrodes. Energy Environ. Sci. 7(2):779-90

55. Andrade L, Lopes T, Aguilar Ribeiro H, Mendes A. 2011. Transient phenomenological modeling of photoelectrochemical cells for water splitting - application to undoped hematite electrodes. Int. F. Hydrogen Energy 36(1):175-88

56. Berger A, Segalman RA, Newman J. 2014. Material requirements for membrane separators in a watersplitting photoelectrochemical cell. Energy Environ. Sci. 7:1468-76

57. Carver C, Ulissi Z, Ong CK, Dennison S, Kelsall GH, Hellgardt K. 2012. Modelling and development of photoelectrochemical reactor for $\mathrm{H}_{2}$ production. Int. 7. Hydrogen Energy 37(3):2911-23

58. Singh MR, Stevens JC, Weber AZ. 2014. Design of membrane-encapsulated wireless photoelectrochemical cells for hydrogen production. 7. Electrochem. Soc. 161(8):E3283-96

59. Bolton JR, Strickler SJ, Connolly JS. 1985. Limiting and realizable efficiencies of solar photolysis of water. Nature 316(6028):495-500

60. Fujishima A, Honda K. 1972. Electrochemical photolysis of water at a semiconductor electrode. Nature 238(5358):37-38 
61. Tran PD, Wong LH, Barber J, Loo JSC. 2012. Recent advances in hybrid photocatalysts for solar fuel production. Energy Environ. Sci. 5(3):5902-18

62. Chen X, Liu L, Yu PY, Mao SS. 2011. Increasing solar absorption for photocatalysis with black hydrogenated titanium dioxide nanocrystals. Science 331(6018):746-50

63. Ai G, Sun W-T, Zhang Y-L, Peng L-M. 2011. Nanoparticle and nanorod $\mathrm{TiO}_{2}$ composite photoelectrodes with improved performance. Chem. Commun. 47(23):6608-10

64. Chen X, Mao SS. 2007. Titanium dioxide nanomaterials: synthesis, properties, modifications, and applications. Chem. Rev. 107(7):2891-959

65. Bora DK, Braun A, Constable EC. 2013. "In rust we trust." Hematite-the prospective inorganic backbone for artificial photosynthesis. Energy Environ. Sci. 6(2):407-25

66. Sivula K, Le Formal F, Grätzel M. 2011. Solar water splitting: progress using hematite $\left(\alpha-\mathrm{Fe}_{2} \mathrm{O}_{3}\right)$ photoelectrodes. Chemsuschem 4(4):432-49

67. Warren SC, Voïtchovsky K, Dotan H, Leroy CM, Cornuz M, et al. 2013. Identifying champion nanostructures for solar water-splitting. Nat. Mater. 12(9):842-49

68. Kim JY, Magesh G, Youn DH, Jang J-W, Kubota J, et al. 2013. Single-crystalline, wormlike hematite photoanodes for efficient solar water splitting. Sci. Rep. 3:2681

69. Coridan RH, Shaner M, Wiggenhorn C, Brunschwig BS, Lewis NS. 2013. Electrical and photoelectrochemical properties of $\mathrm{WO}_{3} / \mathrm{Si}$ tandem photoelectrodes. F. Phys. Chem. C 117(14):6949-57

70. Spurgeon JM, Velazquez JM, McDowell MT. 2014. Improving $\mathrm{O}_{2}$ production of $\mathrm{WO}_{3}$ photoanodes with $\mathrm{IrO}_{2}$ in acidic aqueous electrolyte. Phys. Chem. Chem. Phys. 16(8):3623-31

71. Luo W, Yang Z, Li Z, Zhang J, Liu J, et al. 2011. Solar hydrogen generation from seawater with a modified $\mathrm{BiVO}_{4}$ photoanode. Energy Environ. Sci. 4(10):4046-51

72. Abdi FF, van de Krol R. 2012. Nature and light dependence of bulk recombination in Co-Pi-catalyzed BiVO $_{4}$ photoanodes. F. Phys. Chem. C 116(17):9398-404

73. Long MC, Cai WM, Kisch H. 2007. Visible light induced photoelectrochemical properties of n-BiVO and $\mathrm{n}-\mathrm{BiVO}_{4} / \mathrm{p}-\mathrm{Co}_{3} \mathrm{O}_{4}$. F. Phys. Chem. C 112(2):548-54

74. Alarcón-Lladó E, Chen L, Hettick M, Mashouf N, Lin Y, et al. 2014. $\mathrm{BiVO}_{4}$ thin film photoanodes grown by chemical vapor deposition. Phys. Chem. Chem. Phys. 16(4):1651-57

75. Lichterman MF, Shaner MR, Handler SG, Brunschwig BS, Gray HB, et al. 2013. Enhanced stability and activity for water oxidation in alkaline media with bismuth vanadate photoelectrodes modified with a cobalt oxide catalytic layer produced by atomic layer deposition. 7. Phys. Chem. Lett. 4(23):4188-91

76. Khaselev O, Bansal A, Turner JA. 2001. High-efficiency integrated multijunction photovoltaic/ electrolysis systems for hydrogen production. Int. 7. Hydrogen Energy 26(2):127-32

77. Lin Y, Battaglia C, Boccard M, Hettick M, Yu Z, et al. 2013. Amorphous Si thin film based photocathodes with high photovoltage for efficient hydrogen production. Nano Lett. 13(11):5615-18

78. Boettcher SW, Spurgeon JM, Putnam MC, Warren EL, Turner-Evans DB, et al. 2010. Energyconversion properties of vapor-liquid-solid-grown silicon wire-array photocathodes. Science 327(5962):185-87

79. Maiolo JR, Kayes BM, Filler MA, Putnam MC, Kelzenberg MD, et al. 2007. High aspect ratio silicon wire array photoelectrochemical cells. 7. Am. Chem. Soc. 129(41):12346-47

80. Hernández-Pagan EA, Vargas-Barbosa NM, Wang TH, Zhao Y, Smotkin ES, Mallouk TE. 2012. Resistance and polarization losses in aqueous buffer-membrane electrolytes for water-splitting photoelectrochemical cells. Energy Environ. Sci. 5:7582-89

81. Jin J, Walczak K, Singh MR, Karp C, Lewis N, Xiang C. 2014. An experimental and modeling/simulationbased evaluation of the efficiency and operational performance characteristics of an integrated, membrane-free, neutral pH solar-driven water-splitting system. Energy Environ. Sci. 7:3371-80

82. Delacourt C, Ridgway PL, Kerr JB, Newman J. 2008. Design of an electrochemical cell making syngas $\left(\mathrm{CO}+\mathrm{H}_{2}\right)$ from $\mathrm{CO}_{2}$ and $\mathrm{H}_{2} \mathrm{O}$ reduction at room temperature. 7 . Electrochem. Soc. 155(1):B42-49

83. Döscher H, GeiszJF, Deutsch TG, Turner JA. 2014. Sunlight absorption in water-efficiency and design implications for photoelectrochemical devices. Energy Environ. Sci. 7:2951-56

84. Hu S, Shaner MR, Beardslee JA, Lichterman M, Brunschwig BS, Lewis NS. 2014. Amorphous TiO 2 coatings stabilize Si, GaAs, and GaP photoanodes for efficient water oxidation. Science 344(6187):1005-9 
85. Rodriguez CA, Modestino MA, Psaltis D, Moser C. 2014. Design and cost considerations for practical solar-hydrogen generators. Energy Environ. Sci. 7(12):3828-35

86. Gibson TL, Kelly NA. 2008. Optimization of solar powered hydrogen production using photovoltaic electrolysis devices. Int. 7. Hydrogen Energy 33(21):5931-40

87. Lehman PA, Chamberlin CE, Pauletto G, Rocheleau MA. 1997. Operating experience with a photovoltaic-hydrogen energy system. Int. F. Hydrogen Energy 22(5):465-70

88. Vidueira JM, Contreras A, Veziroglu TN. 2003. PV autonomous installation to produce hydrogen via electrolysis, and its use in FC buses. Int. 7. Hydrogen Energy 28(9):927-37

89. Kelly NA, Gibson TL, Ouwerkerk DB. 2008. A solar-powered, high-efficiency hydrogen fueling system using high-pressure electrolysis of water: design and initial results. Int. F. Hydrogen Energy 33(11):2747-64

90. Brinner A, Bussmann H, Hug W, Seeger W. 1992. Test results of the hysolar $10 \mathrm{~kW}$ PV-electrolysis facility. Int. F. Hydrogen Energy 17(3):187-97

91. Cox CR, Lee JZ, Nocera DG, Buonassisi T. 2014. Ten-percent solar-to-fuel conversion with nonprecious materials. PNAS 111(39):14057-61

92. LuoJ, Im JH, Mayer MT, Schreier M, Nazeeruddin MK, et al. 2014. Water photolysis at $12.3 \%$ efficiency via perovskite photovoltaics and Earth-abundant catalysts. Science 345(6204):1593-96

93. Kuznetsov D. 2013. Hydrogen storage for large-scale renewable energy deployment-EU demonstration projects. Tech. Rep., CleanTechnica

94. Huang Z, Xiang C, Lewerenz H-J, Lewis NS. 2014. Two stories from the ISACS 12 conference: solarfuel devices and catalyst identification. Energy Environ. Sci. 7:1207-11

95. Thompson JR, McConnell RD, Mosleh M. 2005. Cost analysis of a concentrator photovoltaic bydrogen production system. Presented at Int. Conf. Sol. Conc. Gener. Electr. Hydrog., Scottsdale, AZ

96. Biddle JR, Peterson DB, Fujita T. 1985. Solar photochemical process engineering for production of fuels and chemicals. Int. F. Hydrogen Energy 10(10):633-43

97. Zhai P, Haussener S, Ager J, Sathre R, Walczak K, et al. 2013. Net primary energy balance of a solardriven photo-electrochemical water-splitting device. Energy Environ. Sci. 6:2380-89

98. Ozbilen A, Dincer I, Rosen MA. 2013. Comparative environmental impact and efficiency assessment of selected hydrogen production methods. Environ. Impact Assess. Rev. 42:1-9

99. Sathre R, Scown CD, Morrow WR III, Stevens JC, Sharp ID, et al. 2014. Life-cycle net energy assessment of large-scale hydrogen production via photoelectrochemical water splitting. Energy Environ. Sci. 7:326478

100. Van Noorden R. 2012. 'Artificial leaf' faces economic hurdle. Nat. News, May 23

101. Feldman D, Barbose G, Margolis RM, Wiser R, Darghouth N, Goodrich A. 2012. Photovoltaic (PV) pricing trends: historical, recent, and near-term projections. Tech. Rep., US Dep. Energy

102. IRENA. 2012. Renewable energy technologies: cost analysis series: solar photovoltaics. Tech. Rep., IRENA. http://www.irena.org/DocumentDownloads/Publications/RE_Technologies_Cost_AnalysisSOLAR_PV.pdf

103. Gregoire JM, Xiang C, Liu X, Marcin M, Jin J. 2013. Scanning droplet cell for high throughput electrochemical and photoelectrochemical measurements. Rev. Sci. Instrum. 84(2):024102

104. Gregoire JM, Xiang C, Mitrovic S, Liu X, Marcin M, et al. 2013. Combined catalysis and optical screening for high throughput discovery of solar fuels catalysts. F. Electrochem. Soc. 160(4):F337-42

105. Xiang C, Suram SK, Haber JA, Guevarra DW, Soedarmadji E, et al. 2014. High-throughput bubble screening method for combinatorial discovery of electrocatalysts for water splitting. ACS Comb. Sci. 16(2):47-52. PMID: 24372547

106. Xiang C, Haber J, Marcin M, Mitrovic S, Jin J, Gregoire JM. 2014. Mapping quantum yield for (Fe-Zn$\mathrm{Sn}-\mathrm{Ti}) \mathrm{O}_{x}$ photoabsorbers using a high throughput photoelectrochemical screening system. ACS Comb. Sci. 16(3):120-27. PMID: 24471712

107. Spurgeon JM, Walter MG, Zhou J, Kohl PA, Lewis NS. 2011. Electrical conductivity, ionic conductivity, optical absorption, and gas separation properties of ionically conductive polymer membranes embedded with Si microwire arrays. Energy Environ. Sci. 4:1772-80

108. Plass KE, Filler MA, Spurgeon JM, Kayes BM, Maldonado S, et al. 2009. Flexible polymer-embedded Si wire arrays. Adv. Mater. 21(3):325-28 
109. Sun J, Liu C, Yang P. 2011. Surfactant-free, large-scale, solution-liquid-solid growth of gallium phosphide nanowires and their use for visible-light-driven hydrogen production from water reduction. F. Am. Chem. Soc. 133(48):19306-9. PMID: 22050218

110. Hu S, Chi C-Y, Fountaine KT, Yao M, Atwater HA, et al. 2013. Optical, electrical, and solar energyconversion properties of gallium arsenide nanowire-array photoanodes. Energy Environ. Sci. 6:1879-90

111. Modestino MA, Diaz-Botia CA, Haussener S, Gomez-Sjoberg R, Ager JW, Segalman RA. 2013. Integrated microfluidic test-bed for energy conversion devices. Phys. Chem. Chem. Phys. 15:7050-54

112. Kjeang E, Djilali N, Sinton D. 2009. Microfluidic fuel cells: a review. F. Power Sources 186(2):353-69

113. Hara M, Mallouk TE. 2000. Photocatalytic water oxidation by Nafion-stabilized iridium oxide colloids. Chem. Commun. 2000:1903-4

114. Srivastava ON, Karn RK, Misra M. 2000. Semiconductor-septum photoelectrochemical solar cell for hydrogen production. Int. F. Hydrogen Energy 25(6):495-503

115. Xiang C, Chen Y, Lewis NS. 2013. Modeling an integrated photoelectrolysis system sustained by water vapor. Energy Environ. Sci. 6:3713-21

116. Spurgeon JM, Lewis NS. 2011. Proton exchange membrane electrolysis sustained by water vapor. Energy Environ. Sci. 4:2993-98

117. Hosseini Hashemi SM, Choi J-W, Psaltis D. 2014. Solar thermal harvesting for enhanced photocatalytic reactions. Phys. Chem. Chem. Phys. 16:5137-41

118. Kelzenberg MD, Boettcher SW, Petykiewicz JA, Turner-Evans DB, Putnam MC, et al. 2010. Enhanced absorption and carrier collection in Si wire arrays for photovoltaic applications. Nat. Mater. 9(3):239-44

119. Zagolla V, Tremblay E, Moser C. 2014. Proof of principle demonstration of a self-tracking concentrator. Opt. Express 22:A498-510

120. Fountaine KT, Kendall CG, Atwater HA. 2014. Near-unity broadband absorption designs for semiconducting nanowire arrays via localized radial mode excitation. Opt. Express 22:A930-40

121. Eisler CN, Abrams ZR, Sheldon MT, Zhang X, Atwater HA. 2014. Multijunction solar cell efficiencies: effect of spectral window, optical environment and radiative coupling. Energy Environ. Sci. 7:3600-5

122. Zagolla V, Dominé D, Tremblay E, Moser C. 2014. Self-tracking solar concentrator with an acceptance angle of $32^{\circ}$. Opt. Express 22(S7):A1880-94

123. Choi J-W, Hosseini Hashemi SM, Erickson D, Psaltis D. 2014. A micropillar array for sample concentration via in-plane evaporation. Biomicrofluidics 8(4):044108 
Annual Review of

Chemical and

Biomolecular

Engineering

\section{Contents}

A Conversation with Adam Heller Adam Heller and Elton 7. Cairns

An Integrated Device View on Photo-Electrochemical

Solar-Hydrogen Generation

Miguel A. Modestino and Sophia Haussener.

Synthetic Biology for Specialty Chemicals

Kelly A. Markham and Hal S. Alper

Chemical Looping Technology: Oxygen Carrier Characteristics

Siwei Luo, Liang Zeng, and Liang-Shib Fan

Gasification of Woody Biomass

Fianjun Dai, Fean Saayman, Fohn R. Grace, and Naoko Ellis

Design Criteria for Future Fuels and Related Power Systems Addressing the Impacts of Non- $\mathrm{CO}_{2}$ Pollutants on Human Health and Climate Change Fames Fay Schauer

Graphene Mechanics: Current Status and Perspectives

Costas Galiotis, Otakar Frank, Emmanuel N. Koukaras, and Dimitris Sfyris

Smart Manufacturing

Fim Davis, Thomas Edgar, Robert Graybill, Prakashan Korambath, Brian Schott,

Denise Swink, Fianwu Wang, and fim Wetzel

Current Trends and Challenges in Biointerfaces Science and Engineering A.M. Ross and F. Labann

Defects in the Self-Assembly of Block Copolymers and Their Relevance for Directed Self-Assembly Weibua Li and Marcus Müller.

Clean Water for Developing Countries

Aniruddha B. Pandit and Fyoti Kishen Kumar 
Thermoelectric Properties of Solution Synthesized

Nanostructured Materials

Scott W. Finefrock, Haoran Yang, Haiyu Fang, and Yue Wu

Group Contribution Methods for Phase Equilibrium Calculations

Fürgen Gmebling, Dana Constantinescu, and Bastian Schmid

Microfluidic Strategies for Understanding the Mechanics of Cells and Cell-Mimetic Systems

Joanna B. Dabl, Jung-Ming G. Lin, Susan 7. Muller, and Sanjay Kumar

Biocatalysis: A Status Report

Andreas S. Bommarius

Computational Modeling of Multiphase Reactors

7.B. Foshi and K. Nandakumar.

Particle Formation and Product Formulation Using Supercritical Fluids Željko Knez, Maša Knez Hrnčič, and Mojca Škerget. ...

\section{Indexes}

Cumulative Index of Contributing Authors, Volumes 2-6 409

Cumulative Index of Article Titles, Volumes 2-6

\section{Errata}

An online log of corrections to Annual Review of Chemical and Biomolecular Engineering articles may be found at http://www.annualreviews.org/errata/chembioeng 